general IDSA membershin noted that they spent significant time in infection control or hospital epidemiology. Most received compensation for their time. In addition to their work with infection control committees, IDSA members also spent a great deal of time on pharmacy and therapeutics committees and quality assurance activities.

The Publications Committee, chaired by Dr. William Scheckler, with members Drs. Eli Abrutyn, Walter Hierholzer, and Richard Dixon, is reviewing the status of our journal and analyzing our contract with SLACK, which is due for renewal in 1990.

Lorraine Harkavey, past-president of APIC, presented a report from APIC. She noted that CDC has discontinued, at least temporarily, its course for infection control practitioners. Consequently, APIC is developing its own week-long course for beginning infection control practitioners and will debut this course in Chicago in April.

\section{IDSA Liaison Report}

Dr. William Scheckler reported on the activities of the IDSA
Clinical Affairs Committee. The IDSA Counsel has approved an official motion endorsing the planned regional Clinical Affairs Committee-sponsored course for infectious disease specialists, which will be held in San Diego, January 1990. The possibility of joint sponsorship between IDSA and SHEA for regional conferences is being explored.

\section{SHEA Annual Luncheon Meeting}

For those of you who like to plan ahead, please note that the SHEA Annual Meeting and Luncheon will be held Tuesday, Sept 19, 1989 during the ICAAC meetings in Houston, Texas. Further information regarding our annual meeting will be published in the Newsletter this summer.

\section{SHEA Directory- Update}

The SHEA directory is scheduled for republication in 1989. If your address or phone number is incorrect in, or has been omitted from the current directory, please notify Dr. Timothy Townsend, SHEA Secretary, of your corrections as soon as possible.

\section{SHEA Associates- The Cost-Effective Approach}

SHEA encourages infectious diseases fellows to join its ranks and receive the journal as Associate Members. Infectious disease fellows wishing to take advantage of this reduced-rate category for trainees should contact SHEA secretary, Dr. Timothy Townsend, Brady 119, Johns Hopkins Hospital, $600 \mathrm{~N}$. Wolfe St., Baltimore, MD 21205.

Brief items of interest for the SHEA NeatsIntler man be sent to Robert A. Weinstein. (1I), SHEA Neasletter Editor, Division of Infectious Diseases, Michael Reese Hospital. Lake Shore Drize at 31st St. Chicago. IL. 60616. Copy must be typed, doublespeced, and mey not excepd fire pages. 